\title{
PAR conversion efficiencies of a tropical rain forest
}

\author{
R.J. Luxmoore ${ }^{1}$ and J.G. Saldarriaga ${ }^{2}$ \\ 1 Environmental Sciences Division, Oak Ridge National Laboratory, Oak Ridge, TN, U.S.A., and \\ 2 Tropenbos Program, Bogotá, Colombia
}

\section{Introduction}

The mean annual quantities of photosynthetically active radiation (PAR) absorbed during various stages of regeneration of a tropical rain forest in the upper Rio Negro region of Colombia and Venezuela were estimated for the intervals between clearcut and $1,3,10,20,35,60,80$, and $200 \mathrm{yr}$ of growth. The forest phytomass and litterfall at each stage were obtained from previous studies, and the data were used to calculate the mean annual quantity of net dry matter production per unit of absorbed PAR, the PAR conversion efficiency.

\section{Methods}

The basic equation for the calculation is given by:

\begin{tabular}{|c|c|}
\hline $\begin{array}{l}\text { Total dry matter }= \\
\text { production } \\
\left(\mathrm{g}^{-2} \mathrm{~m}^{-2} \cdot \mathrm{yr}^{-1}\right)\end{array}$ & $\begin{array}{c}\text { PAR conversion } \\
\text { efficiency } \\
\left(g \cdot M J^{-1}\right)\end{array}$ \\
\hline
\end{tabular}

Saldarriaga et al. (1986) investigated forest succession at 23 sites representing a chronosequence ranging from recently abandoned areas after slash-and-burn agriculture to mature rain forest. Aboveground and belowground living phytomass, litter and root production, standing dead mass, and leaf area indices were estimat- ed with allometric regression relationships using diameter, height, dry weight and wood density data from each of the 23 sites. Recently available data for 1 and $3 \mathrm{yr}$ regrowth forest stands were also included in this analysis.

Regression equations for converting leaf phytomass to leaf area were used with number of trees per hectare (Saldarriaga et al., 1986) to derive leaf area index ( $L A I)$ values for the forest stands. The value of $L A l$ for the $1-3 \mathrm{yr}$ period was 3.9, and this increased up to a mean value of 6.7 for the oldest stand $(80-200 \mathrm{yr})$.

\section{Results}

The annual quantities of PAR absorbed by the forest stands (Table I) were calculated from the Bouguer-Lambert (Beers) Law using appropriate $L A I$ values with an extinction coefficient for PAR of 0.74 and an annual net incoming PAR of 2.75 $\mathrm{GJ} \cdot \mathrm{m}^{-2} \cdot \mathrm{yr}^{-1}$. This latter value was obtained from the mean annual solar radiation (5.2 GJ. $\mathrm{m}^{-2} \cdot \mathrm{yr}^{-1}$ ) measured in the area since 1971 , by using a factor of 0.55 for the proportion of PAR (Stigter and Musabilha, 1982) and a PAR albedo of 0.04 (Dickinson, 1983).

Dry matter production for the 8 growth periods (Fig. 1) shows the highest rates during the first $10 \mathrm{yr}$. A significant change 
Table I. Mean leaf area indices for periods of forest succession and the estimated annual PAR absorption by the vegetation.

\begin{tabular}{lllllllll}
\hline & \multicolumn{2}{l}{ Period $(y r)$} & & & & & \\
\cline { 2 - 7 } & $0-1$ & $1-3$ & $3-10$ & $10-20$ & $20-35$ & $35-60$ & $60-80$ & $80-200$ \\
\hline $\begin{array}{l}\text { Mean } L A I \\
\left(\mathrm{~m}^{2} \cdot \mathrm{m}^{-2}\right)\end{array}$ & $2.3^{\mathrm{a}}$ & 3.9 & 4.5 & 6.0 & 6.1 & 6.2 & 6.3 & 6.7 \\
$\begin{array}{l}\text { PAR absorbed } \\
\left(\mathrm{GJ} \cdot \mathrm{m}^{-2} \cdot \mathrm{yr}^{-1}\right)\end{array}$ & 2.23 & 2.59 & 2.65 & 2.72 & 2.72 & 2.72 & 2.72 & 2.73 \\
\hline
\end{tabular}

a One-hall of the maximum value for the 1 st yr $L A /$ due to herbaceous component (Uhl, 1987); other $L A /$ data from Saldarriaga et al. (1986) and Saldarriaga (unpublished).

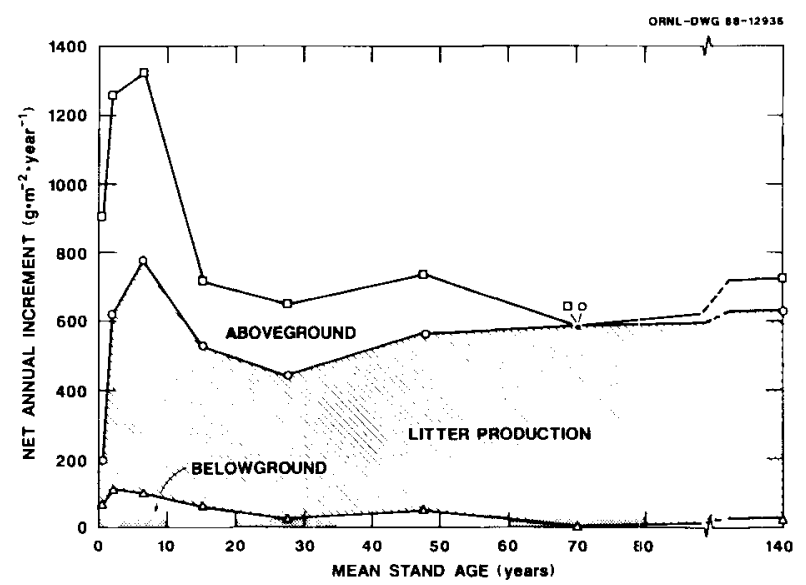

Fig. 1. Annual dry matter increments of above- and belowground living phytomass and litter production for 8 growth periods of a tropical rain forest.

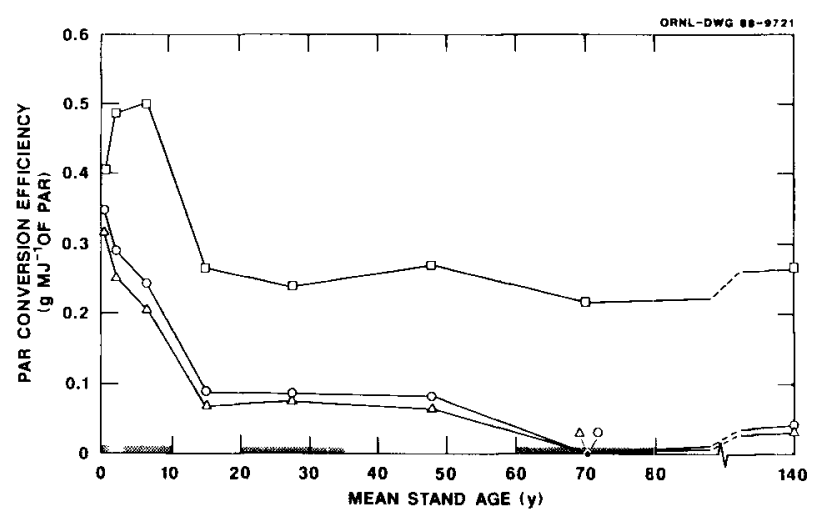

Fig. 2. PAR conversion efficiency based on aboveground living phytomass ( $\Delta$ ), above- and belowground phytomass $(O)$ and net primary production $(ב)$. 
in stand structure occurs at about $60-80$ $\mathrm{yr}$ with the replacement of several early successional species by the mature stand species. This results in no increment in the living phytomass.

The PAR conversion efficiencies determined from eqn 1 show the highest values in the first year, decreasing to zero by year 70 (Fig. 2). When above- and belowground production is combined with litterfall (net primary production), the PAR conversion efficiencies are much higher for years 20-140.

\section{Discussion and Conclusion}

The PAR conversion efficiency values for aboveground growth are very much lower than the $1.7 \mathrm{~g} \cdot \mathrm{MJ}^{-1}$ reported by Linder (1985) for several temperate forests; however, the results are consistent with the low-end values in the $0.2-1.0 \mathrm{~g} \cdot \mathrm{MJ}^{-1}$ range of PAR energy conversion values derived from Jordan (1971) for 17 forest types, including temperate and tropical ecosystems. The analysis by Jordan included coarse roots in the dry matter production. A value of $20 \mathrm{~kJ} \cdot \mathrm{g}^{-1}$ for the heat of combustion of dry matter, as suggested by Leith (1968), was used in the conversion of Jordan's values from an energy to a mass basis.

This analysis shows that PAR conversion efficiency decreases with the increase in successional stage and that efficiency values are generally low in comparison with data for temperate forests. One implication for agroforestry in tropical areas similar to the upper Rio Negro valley is that short rotation times $(<10 \mathrm{yr})$ are desirable so that relatively high energy conversion into aboveground phytomass can be obtained.

\section{Acknowledgments}

The authors thank the staff of the Ministry of Environment at San Carlos de Rio Negro, Venezuela, for providing solar radiation data. Research was sponsored in part by the $\mathrm{Na}$ tional Science Foundation's Ecosystem Studies Program under Interagency Agreement no. BSR-831585 with the U.S. Department of Energy and in part by the Carbon Dioxide Research Division, Office of Basic Energy Sciences, U.S. Department of Energy, under contract DEAC05-840R21400 with Martin Marietta Energy Systems, Inc. The research is a contribution to the Solar Conversion Project of the International Union of Forestry Research Organizations. Publication no. 3182, Environmental Sciences Division, ORNL.

\section{References}

Dickinson R.E. (1983) Land surface processes and climate - surface albedos and energy balance. Adv. Geophys. 25, 305-355

Jordan C.F. (1971) Productivity of tropical forest and its relations to a world pattern of energy storage. J. Ecol. 59, 127-142

Leith $H$. (1968) Calorific values of biological materials. In: UNESCO Symposium on the Functioning of Terrestrial Ecosystems. UNESCO, Paris, pp. 233-240

Linder S. (1985) Potential and actual production in Australian forest stands. In: Research for Forest Management. (Landsberg J.J. \& Parsons W., eds.), CSIRO, Melbourne, pp. 11-34

Saldarriaga J.G., West D.C. \& Tharp M.L. (1986) Forest succession in the Upper Rio Negro of Colombia and Venezuela. ORNL/TM9712. Oak Ridge National Laboratory, Oak Ridge, TN, pp.164

Stigter C.J. \& Musabilha V.M.M. (1982) The conservative ratio of photosynthetically active to total radiation in the tropics. J. Appl. Ecol. 19, 853-858

Uhl C. (1987) Factors controlling succession following slash-and-burn agriculture in Amazonia. J. Ecol. $75,377-407$ 